\title{
Estiolamento e luz artificial no cultivo in vitro de orquídeas nativa e híbrida
}

\author{
Etiolation and artificial light in native and hybrid orchids under in vitro cultivation
}

\author{
Joyce Dória Rodrigues Soares ${ }^{I^{*}}$ Moacir Pasqual $^{\mathrm{I}}$ Filipe Almendagna Rodrigues ${ }^{\mathrm{I}}$ \\ Aparecida Gomes de Araujo
}

RESUMO

O uso de mudas micropropagadas de orquídeas encontra-se bastante difundido no mercado florístico, uma vez que o ciclo reprodutivo desta é significativamente reduzido. Assim sendo, objetivou-se avaliar a influência de ambientes de cultivo e de concentrações de BAP (6-benzilaminopurina) $e$ ANA (ácido naftaleno acético) em relação à brotação e ao crescimento de plântulas de orquídea nativa (Laelia crispata) $e$ de um híbrido [(Laeliacattleya Culminant "Tuilerie" $x$ Laeliacattleya Sons Atout Rotunda) x Bassolaelia Cattleya Startifire Moon Beach], para redução dos custos de produção e melhoria na qualidade das mudas. Plântulas oriundas de sementes germinadas in vitro com aproximadamente $0,6 \mathrm{~cm}$ de comprimento foram inoculadas em tubos de ensaio contendo $15 \mathrm{~mL}$ de meio de cultura $M S$, acrescido de BAP $(0 ; 2,0$ e 4,0mg $\left.L^{-1}\right)$, ANA $\left(0 ; 1,0\right.$ e 2,0mg $\left.L^{-1}\right)$ e ambientes de cultivo (escuro e sala de crescimento com luz artificial), em todas as combinações possíveis. Ao final de 150 dias, foram realizadas avaliações fitotécnicas quanto ao número de brotos, folhas e de internós, e comprimento médio da parte aérea. O número de brotos e de internós em plântulas da orquídea (nativa e híbrida) foi significativamente superior no ambiente em ausência de luz independente da concentração do fitorregulador utilizado, e a espécie nativa apresentou maior número de internós com a utilização de 2,0mgL $L^{-1}$ de ANA na ausência de $B A P$, e a orquídea híbrida apresentou maior número de internós com a utilização de $2,0 \mathrm{mgL}^{-1}$ de ANA.

Palavras-chave: Orchidaceae, micropropagação, ambiente de cultivo.

\section{ABSTRACT}

The use of micropropagated orchid seedlings is very widespread in floristic broadcast market, since the reproductive cycle of the same is significantly reduced.
Therefore, this study aimed to evaluate the influence of environments for growing concentrations of BAP (benzylaminopurine) and NAA (naphthalene acetic acid) in relation to the budding and growth of seedlings of native orchids (Laelia crispata), and hybrid [(Laeliacattleya Culminant "Tuilerie" x Laeliacattleya Sons Atout Rotunda) $x$ Bassolaelia Cattleya Startifire Moon Beach] to reduce production costs and improved quality of seedlings. Seedlings from seeds germinated in vitro with approximately $0.6 \mathrm{~cm}$ long and were inoculated in test tubes containing $15 \mathrm{~mL}$ of culture medium MS plus BAP $\left(0,2.0\right.$ and 4.0mg L $\left.{ }^{-1}\right), N A A(0,1.0$ and $2.0 \mathrm{mg} \mathrm{L} \mathrm{L}^{-1}$ ) and the growing environment (dark and growth room with artificial light) in all possible combinations. At the end of 150 days, the number of shoots, leaves and internodes and the average length of shoots were evaluated. The number of shoots and internodes in orchid seedlings (native and hybrid) was significantly higher in the environment in the absence of light independent of the concentration of plant growth regulator used. The native species had higher number of internodes with the use of $2.0 \mathrm{mgL}^{-1} \mathrm{NAA}$ in the absence of BAP, and the hybrid orchid showed a higher number of inmates with the use of 2.0mgL $L^{-1} N A A$.

Key words: Orchidaceae, micropropagation, environment of cultivation.

\section{INTRODUÇÃO}

Em condições naturais, a propagação de orquídeas se dá pela proliferação de mudas laterais (brotações) ou pela disseminação natural das sementes, as quais são produzidas em cápsulas. Um fator que contribui para a dificuldade da propagação das

'Programa de Pós-graduação em Fitotecnia, Departamento de Agricultura (DAG), Universidade Federal de Lavras (UFLA), 37200 000, Lavras, MG, Brasil. E-mail: joycerodrigues01@yahoo.com.br. *Autor para correspondência. 
orquídeas em condições naturais é a baixa ou nula germinação de suas sementes na ausência de micorrizas. Naturalmente, ocorre a deiscência das cápsulas, e as sementes são lançadas no ambiente e, ao entrarem em contato com as micorrizas nas raízes das plantas adultas da mesma espécie, se associam e germinam (RAMOS \& CARNEIRO, 2007).

Assim sendo, germinação in vitro vem sendo utilizada com sucesso desde a década de sessenta, quando se obteve a germinação assimbiótica de sementes de orquídeas (KNUDSON, 1946). Nos anos subsequentes, outros métodos de micropropagação, utilizando as mais diferentes fontes de explantes, foram testados com sucesso. A micropropagação é uma alternativa que maximiza a propagação de várias espécies, tendo como vantagens a fixação de ganhos genéticos em populações clonais e a obtenção de grande número de plantas sadias e de alta qualidade, em pequeno espaço físico e em curto tempo, independentemente de fatores climáticos limitantes (GRATTAPAGLIA\& MACHADO, 1998).

O estiolamento proporciona desenvolvimento de brotos e caules na ausência de luz, causando alongamento e coloração amarela ou branca em razão da ausência de clorofila; assim sendo, pode-se ampliar a taxa de multiplicação, uma vez que, além das brotações laterais, cada nó apresenta uma gema lateral, que poderá dar origem a um novo broto ou explante (KERBAUY et al., 1995). SUZUKI et al. (2004) afirma que plantas de Catasetum fimbriatum, quando cultivadas in vitro no escuro, apresentam estiolamento caulinar, podendo seus segmentos nodais serem utilizados para a propagação vegetativa.

$\mathrm{O}$ estiolamento tem sido utilizado com sucesso na micropropagação de outras espécies cultivadas. Em abacaxizeiro (Ananas comosus), cultivar 'Pérola', MOREIRA et al. (2003) obtiveram 10,26 brotações, após 40 dias de cultivo in vitro no escuro, utilizando meio MS+1,8mg L-1 ANA (ácido naftaleno acético)+2,0 $\mathrm{mg} \mathrm{L}^{-1}$ BAP (6-benzilaminopurina), e os maiores brotos estiolados $(10,86 \mathrm{~cm}$ em média) foram produzidos na ausência de fitorreguladores. Após 60 dias de cultivo in vitro, na ausência de luz, BARBOZA \& CALDAS (2001) obtiveram em média 11,3 brotos para o híbrido PESC 52 de abacaxizeiro. Verificaram, ainda, que a adição de ANA e AIA (ácido 3-idolacético) não foi eficiente para estimular a formação de brotos estiolados.

Este trabalho teve como objetivo avaliar a influência de ambientes de cultivo e de concentrações de fitorreguladores em relação à brotação e ao crescimento de plântulas de orquídea nativa (Laelia crispata $)$ e de um híbrido [(Laeliacattleya Culminant
"Tuilerie" x Laeliacattleya Sons Atout Rotunda) x Bassolaelia Cattleya Startifire Moon Beach].

\section{MATERIAL E MÉTODOS}

O material vegetal constou de plântulas de uma espécie nativa de orquídea (Laelia crispata) e de um híbrido [(Laeliacattleya Culminant "Tuilerie" $\mathrm{x}$ Laeliacattleya Sons Atout Rotunda) x Bassolaelia Cattleya Startifire Moon Beach], advindas de germinação in vitro de sementes oriundas de autofecundação (nativa) ou polinização cruzada (híbrido). As sementes foram germinadas em meio de cultura Knudson C (1946) modificado em $\mathrm{ZnSO}_{4} \cdot 7 \mathrm{H}_{2} \mathrm{O}$ (de 0,331 para 6,62 $\left.\mathrm{mg} \mathrm{L}^{-1}\right), \mathrm{H}_{3} \mathrm{BO}_{3}$ (de 0,056 para $1,4 \mathrm{mg}$ $\left.\mathrm{L}^{-1}\right)$ e $\mathrm{MnSO}_{4} \mathrm{H}_{2} \mathrm{O}\left(\right.$ de 7,5 para $\left.15 \mathrm{mg} \mathrm{L}^{-1}\right)$, onde permaneceram por três meses. Após esse período, cada plântula de aproximadamente $0,5 \mathrm{~cm}$ de comprimento foi inoculada em tubo de ensaio contendo $15 \mathrm{~mL}$ de meio de cultura MS (MURASHIGE \& SKOOG, 1962), acrescido de BAP $\left(0 ; 2,0\right.$ e $\left.4,0 \mathrm{mg} \mathrm{L}^{-1}\right)$ e ANA $(0 ; 1,0$ e $2,0 \mathrm{mg} \mathrm{L}^{-1}$ ), em dois ambientes de cultivo (sala de crescimento sob luz artificial e sob ausência completa de luz), em todas as combinações possíveis. O meio de cultura teve seu $\mathrm{pH}$ ajustado para 5,8 $\pm 0,1$ e solidificado com 5,5 $\mathrm{g} \mathrm{L}^{-1}$ de ágar antes do processo de autoclavagem a $121^{\circ} \mathrm{C} \mathrm{e} 1 \mathrm{~atm}$, por 20 minutos.

$\mathrm{O}$ ambiente de cultivo do trabalho foi sala de crescimento com iluminação artificial fornecida por lâmpadas fluorescentes do tipo luz do dia especial (OSRAM 20W), irradiância de $42 \mathrm{~W} \mathrm{~m}^{-2}$, fotoperíodo de 16 horas e temperatura de $25 \pm 2^{\circ} \mathrm{C}$. Para a indução do estiolamento, parte das culturas foram mantidas também em sala de crescimento, mas sob ausência de luz, mantendo-se a mesma temperatura. Depois de decorrido o período de incubação no escuro, as plântulas foram retiradas dessa condição e submetidas à iluminação artificial, para monitoramento do período de aquisição de coloração.

As avaliações fitotécnicas foram realizadas ao final de 150 dias, quando foram avaliados número de brotos, comprimento da parte aérea $(\mathrm{cm})$ e número de internós. O delineamento experimental foi o inteiramente casualizado, tanto no experimento com orquídea nativa (Laelia crispata), quanto com o híbrido [(Laeliacattleya Culminant "Tuilerie" $\mathrm{x}$ Laeliacattleya Sons Atout Rotunda) x Bassolaelia Cattleya Startifire Moon Beach], ambos em esquema fatorial $3 \times 3 \times 2$, sendo três concentrações de BAP, três concentrações de ANA e dois ambientes de cultivo, com 12 plântulas por tratamento.

Os dados obtidos foram submetidos à análise de variância e análise conjunta dos ambientes. 
Para isso, o programa estatístico Sisvar 4.3 (FERREIRA, 2008) foi utilizado, sendo as médias comparadas pelo teste $\mathrm{F}$, a $5 \%$ de probabilidade.

\section{RESULTADOS E DISCUSSÃO}

Decorrido o período de incubação, observou-se que grande parte das plântulas que estavam em condições de ausência de luz mostrava o fenótipo de plantas estioladas e aclorofiladas, ou seja, caules esbranquiçados, com aspecto translúcido, apresentando as folhas pequenas e os entrenós mais longos. Em todos os tratamentos, surgiram novas brotações a partir da base e/ou nos nós, as quais também se apresentavam estioladas. TAIZ \& ZEIGER (2004) citam a ocorrência dessas características em plantas mantidas no escuro por determinado tempo, e nesses casos há inibição do desenvolvimento de cloroplastos e diminuição nos conteúdos de pigmentos fotossintéticos. RAVEN et al. (2001) ratificaram essas afirmações, acrescentando que tais plantas, quando colocadas na presença de luz, retomam a expansão e o desenvolvimento normal.

As plântulas estioladas, assim que retornaram às condições de luminosidade, foram adquirindo a coloração verde (Figura 1) e apresentaram aspecto translúcido quando mantidas na ausência de luz (Figura 1A e 1E), provavelmente, à medida que a

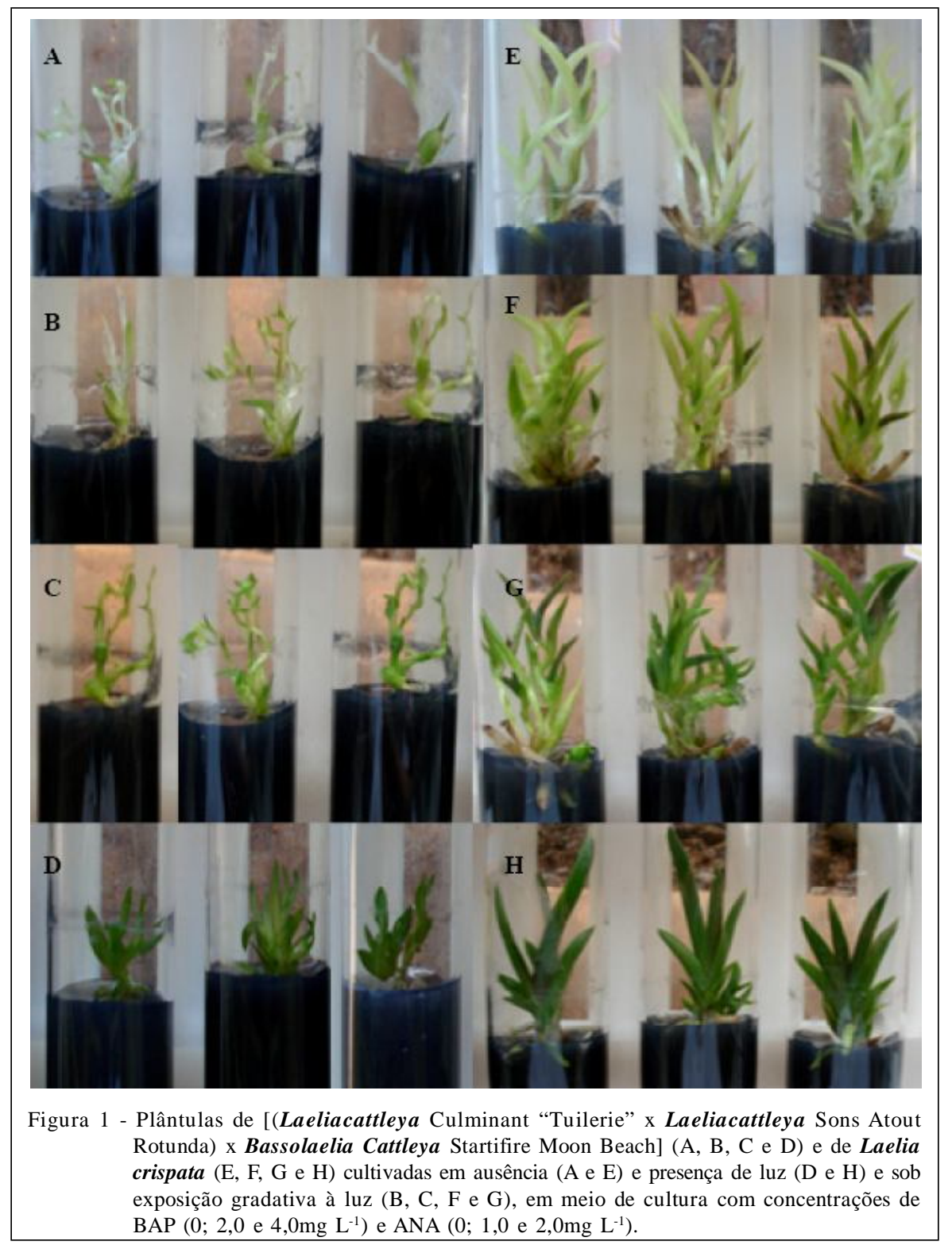

Ciência Rural, v.40, n.9, set, 2010. 
ontogênese de cloroplastídeos foi realizada (TAIZ \& ZEIGER, 2004), as plantas adquiriram um aspecto de pigmentação crescente dos 20 (Figura $1 \mathrm{~B} \mathrm{e} \mathrm{F)} \mathrm{aos} 40$ dias após o retorno à luz (Figura $1 \mathrm{C} \mathrm{e} \mathrm{1G).} \mathrm{As} \mathrm{plântulas}$ mantidas sob luz artificial em sala de crescimento apresentaram desenvolvimento fotossintético normal, quando comparadas às plântulas estioladas, as quais, devido à ausência de luz, não possuem pigmentos fotossintetizantes, nesse caso a clorofila. Porém, como nãoé característica para ambas as espécies, não houve crescimento em internós, e as folhas surgiram apenas do explante inicial, o que caracteriza uma desvantagem em termos de produção massal de mudas (Figura 1).

Nenhuma interação tripla foi observada entre os fatores analisados (ambiente x BAP x ANA) para o cultivo in vitro em ambas as espécies de orquídeas. Nessa condição, ocorreram somente interações duplas entre ambiente $\mathrm{x}$ BAPe ambiente $\mathrm{x}$ ANA para todas as variáveis analisadas.

O número de brotos em plântulas da orquídea nativa foi significativamente superior no escuro independente da concentração do fitorregulador utilizado. Analisando-se o ambiente de cultivo no escuro, não houve diferença significativa para as concentrações de BAP; porém, foi observada significância para as concentrações de ANA, e o acréscimo de $2,0 \mathrm{mg} \mathrm{L}^{-1}$ ao meio de cultivo mostrou-se benéfico, obtendo-se em média 3,15 brotos (Tabela 1A). Em relação ao híbrido de orquídea, o mesmo comportamento para o fator ambiente foi observado; porém, houve significância para o fator BAP em ausência de luz, e maior número de brotos foi obtido com a utilização de $2,0 \mathrm{mg} \mathrm{L}^{-1}$ de BAP, já para o fator ANA maiores resultados foram obtidos em sua ausência (Tabela 1A).

O acréscimo de BAP ao meio de cultura não foi benéfico para a obtenção de brotações da espécie nativa. Esses resultados concordam com SUZUKI et al. (2004) e RAMOS \& CARNEIRO (2007), os quais, trabalhando com Cattleya fimbriatum e Cattleya mesquitae, respectivamente, obtiveram aumento de brotações na ausência de BAP. O nível endógeno de citocininas no escuro é maior do que na presença de luz (SUZUKI et al., 2004). Esse fato pode ter ocorrido também com os explantes de Laelia crispata cultivados sob ausência de luz. Possivelmente, houve aumento excessivo do nível endógeno desse fitorregulador, quando BAP foi utilizado no meio de cultura. A adição de ANA ao meio, ainda no ambiente de ausência de luz, não foi benéfica, proporcionando uma relação

Tabela 1 - (A) Número de brotos, (B) número de internós em plântulas de orquídea nativa e híbrida em diferentes ambientes de cultivo (Luz artificial e escuro) sob a influência de concentrações de BAP e ANA após 150 dias de cultivo in vitro.

\begin{tabular}{|c|c|c|c|c|c|c|c|c|}
\hline \multicolumn{9}{|c|}{ A - Orquídea nativa } \\
\hline \multirow{2}{*}{ Ambiente de cultivo } & \multicolumn{3}{|c|}{ BAP $\left(\mathrm{mg} \mathrm{L}^{-1}\right)$} & \multicolumn{4}{|c|}{-ANA $\left(\mathrm{mg} \mathrm{L}^{-1}\right)$} & \multirow[b]{2}{*}{ Médias } \\
\hline & 0 & 2 & 4 & Médias & 0 & 1 & 2 & \\
\hline Luz & $1,66 \mathrm{bB}$ & $2,35 \mathrm{Aa}$ & $2,23 \mathrm{aB}$ & $2,10 \mathrm{~B}$ & $1,81 \mathrm{bA}$ & $1,91 \mathrm{bB}$ & $2,23 \mathrm{aB}$ & $2,10 \mathrm{~B}$ \\
\hline Escuro & $2,56 \mathrm{aA}$ & $2,67 \mathrm{aA}$ & $2,89 \mathrm{aA}$ & $2,70 \mathrm{~A}$ & $2,48 \mathrm{bA}$ & $2,50 \mathrm{bA}$ & $3,15 \mathrm{aA}$ & $2,70 \mathrm{~A}$ \\
\hline Médias & $2,11 \mathrm{~b}$ & $2,51 \mathrm{a}$ & $2,56 \mathrm{a}$ & & $2,14 \mathrm{~b}$ & $2,20 \mathrm{~b}$ & $2,69 \mathrm{a}$ & \\
\hline $\mathrm{CV}(\%)$ & 25 & & & & & & & \\
\hline Luz & $1,93 \mathrm{aA}$ & $2,16 \mathrm{aA}$ & $1,73 \mathrm{aB}$ & 2,03B & $1,60 \mathrm{bB}$ & $2,23 \mathrm{aA}$ & $2,25 \mathrm{aB}$ & $2,03 \mathrm{~B}$ \\
\hline Escuro & $2,15 \mathrm{bA}$ & $2,21 \mathrm{bA}$ & $2,86 \mathrm{aA}$ & $2,31 \mathrm{~A}$ & $2,86 \mathrm{aA}$ & $2,33 \mathrm{bA}$ & $1,75 \mathrm{cA}$ & $2,31 \mathrm{~A}$ \\
\hline Médias & $2,04 \mathrm{~b}$ & $2,18 \mathrm{a}$ & $2,29 \mathrm{a}$ & & $2,23 \mathrm{a}$ & $2,28 \mathrm{a}$ & $2,00 \mathrm{~b}$ & \\
\hline $\mathrm{CV}(\%)$ & 27 & & & & & & & \\
\hline Luz & $0,00 \mathrm{aB}$ & $0,00 \mathrm{aB}$ & $\begin{array}{l}0,00 \mathrm{aB} \\
\text { - Or }\end{array}$ & $\begin{array}{c}\text { ea nativa } \\
0,00 \mathrm{~B}\end{array}$ & $0,00 \mathrm{aB}$ & $0,00 \mathrm{aB}$ & $0,00 \mathrm{aB}$ & $0,00 \mathrm{~B}$ \\
\hline Escuro & $7,31 \mathrm{aA}$ & $5,83 \mathrm{bA}$ & $6,13 \mathrm{bA}$ & $6,42 \mathrm{~A}$ & $5,55 \mathrm{bA}$ & $6,28 \mathrm{bA}$ & $7,40 \mathrm{aA}$ & $6,42 \mathrm{~A}$ \\
\hline Médias & $3,65 \mathrm{a}$ & $2,91 \mathrm{~b}$ & $3,06 \mathrm{~b}$ & & $2,77 \mathrm{c}$ & $3,14 b$ & $3,7 \mathrm{a}$ & \\
\hline $\mathrm{CV}(\%)$ & 35 & & & & & & & \\
\hline Luz & $0,00 \mathrm{aB}$ & $0,00 \mathrm{aB}$ & $0,00 \mathrm{aB}$ & $\begin{array}{c}\text { híbrida-- } \\
0,00 \mathrm{~B}\end{array}$ & $0,00 \mathrm{aB}$ & $0,00 \mathrm{aB}$ & $0,00 \mathrm{aB}$ & $0,00 \mathrm{~B}$ \\
\hline Escuro & $5,29 \mathrm{aA}$ & $4,71 \mathrm{aA}$ & $5,57 \mathrm{aA}$ & $5,19 \mathrm{~A}$ & $5,36 \mathrm{bA}$ & $5,78 \mathrm{bA}$ & $4,76 \mathrm{aA}$ & $5,19 \mathrm{~A}$ \\
\hline Médias & $2,64 \mathrm{a}$ & $2,35 \mathrm{a}$ & $2,78 \mathrm{a}$ & & $2,68 \mathrm{a}$ & $2,89 \mathrm{a}$ & $2,38 \mathrm{a}$ & \\
\hline $\mathrm{CV}(\%)$ & 40 & & & & & & & \\
\hline
\end{tabular}

Médias seguidas por letras distintas, minúscula na horizontal e maiúscula na vertical, dentro de cada variável, diferem entre si, pelo teste de Tukey, a $5 \%$ de probabilidade. 
citocinina/auxina que fez com que a planta direcionasse parte de seu esforço metabólico para a obtenção de brotações em detrimento ao crescimento.

A adição de citocinina foi benéfica para a obtenção de brotações do híbrido, sendo observadas, portanto, diferenças na capacidade proliferativa das duas espécies. Segundo SUZUKI et al. (2004), tais resultados podem estar associados à interação genótipo e citocinina. Daí a necessidade de se otimizar, a cada genótipo, o nível exógeno ou mesmo o tipo de fitorregulador a ser adicionado ao meio.

A altura da brotação principal da espécie nativa de orquídea apresentou efeito significativo para ambiente e cada um dos fitorreguladores, e em ambos a maior altura foi obtida no escuro, em comparação com o cultivo em presença de luz. Verifica-se que houve efeito negativo dos níveis de BAP em relação ao meio sem essa citocinina no escuro, o que foi caracterizado pela acentuada redução do comprimento à medida que se elevou a concentração desse fitorregulador (Tabela 2). Porém, para o fator ANA, houve efeito positivo para o acréscimo dessa auxina ao meio de cultura com a incubação no escuro, obtendo-se em média $4,33 \mathrm{~cm}$ de altura. Para o híbrido, não houve efeito significativo para o incremento de BAP ao meio de cultura; porém, foi observada significância para as concentrações de ANA com efeito negativo em seu acréscimo, obtendo assim maior altura de brotações sem a adição desses reguladores de crescimento no ambiente de ausência de luz (Tabela 2).

Os resultados da altura da brotação principal na espécie nativa podem ser atribuídos aos efeitos do BAP em quebrar a dominância apical e favorecer a emissão de novos brotos (MOK et al., 2000).
De acordo com GRATTAPAGLIA \& MACHADO (1998), o alongamento pode ser inibido pelo efeito acumulativo do regulador de crescimento presente no meio. Estudos realizados por DINIZ et al. (2003) demonstraram que a adição de BAP no meio de cultura também causou redução no comprimento de brotações de macela [Egletes viscosa (L.) Less.]. Em bananeira (Musa acuminata), SOUZA \& GONÇALVES (1996) verificaram que, em meio de cultura sem a presença de BAP, a cultivar 'Caipira' apresentou forte dominância apical, apresentando crescimento pronunciado, ao contrário aos tratamentos com doses crescentes dessa citocinina, que mostraram aumento no número de brotações. Por sua vez, o acréscimo de ANA demonstrou efeito antagônico ao BAP, proporcionando assim crescimento significativo da brotação principal. SUZUKI et al. (2004), avaliando o estiolamento de Cattleya fimbriatum, obtiveram maior altura da brotação principal com o incremento de auxina ao meio de cultivo.

Por outro lado, não se observou diferença significativa quando foram utilizadas diferentes concentrações de BAP no híbrido cultivado em ausência de luz. Aliado a esse fato, o acréscimo da auxina não foi benéfico para o crescimento. Apesar disso, sabe-se que esta é uma variável importante, pois está diretamente relacionada com o número de nós que serão recuperados em novas brotações, quando colocados em condições de luz (MOREIRA et al., 2003). Em Cattleya fimbriatum, SUZUKI et al. (2004) obteve plantas com caules significativamente maiores, quando incubados na ausência de luz em detrimento à presença de luz, independentemente da natureza do regulador de crescimento e das concentrações utilizadas,

Tabela 2 - Altura da brotação principal $(\mathrm{cm})$ de plântulas de orquídea nativa e híbrida em diferentes ambientes de cultivo (Luz artificial e escuro) sob a influência de concentrações de BAP e ANA após 150 dias de cultivo in vitro.

\begin{tabular}{|c|c|c|c|c|c|c|c|c|}
\hline \multicolumn{9}{|c|}{ Orquídea nativa } \\
\hline \multirow{2}{*}{ Ambiente de cultivo } & \multicolumn{3}{|c|}{ - } & \multicolumn{5}{|c|}{ - } \\
\hline & 0 & 2 & 4 & Médias & 0 & 1 & 2 & Médias \\
\hline Luz & $3,08 \mathrm{aB}$ & $3,21 \mathrm{aA}$ & $3,67 \mathrm{aB}$ & $3,32 \mathrm{~B}$ & $2,79 \mathrm{bB}$ & $3,35 \mathrm{aB}$ & $3,81 \mathrm{aB}$ & $3,32 \mathrm{~B}$ \\
\hline Escuro & $4,30 \mathrm{aA}$ & $3,79 \mathrm{bA}$ & $3,87 \mathrm{bA}$ & $3,39 \mathrm{~A}$ & $3,29 \mathrm{bA}$ & $4,33 \mathrm{aA}$ & $4,35 \mathrm{aA}$ & $3,39 \mathrm{~A}$ \\
\hline Médias & $3,69 \mathrm{a}$ & $3,50 \mathrm{a}$ & $3,77 \mathrm{a}$ & & $3,04 \mathrm{~b}$ & $3,84 \mathrm{a}$ & $4,08 \mathrm{a}$ & \\
\hline $\mathrm{CV}(\%)$ & 14 & & & & & & & \\
\hline Luz & $2,10 \mathrm{aB}$ & $1,87 \mathrm{aB}$ & $1,91 \mathrm{aB}$ & $1,96 \mathrm{~B}$ & $1,96 \mathrm{aB}$ & $1,88 \mathrm{aB}$ & $2,06 \mathrm{aA}$ & $1,96 \mathrm{~B}$ \\
\hline Escuro & $2,60 \mathrm{aA}$ & $2,47 \mathrm{aA}$ & $2,45 \mathrm{aA}$ & $2,51 \mathrm{~A}$ & $2,52 \mathrm{aA}$ & $2,70 \mathrm{aA}$ & $2,29 \mathrm{bA}$ & $2,51 \mathrm{~A}$ \\
\hline Médias & $2,35 \mathrm{a}$ & $2,17 \mathrm{a}$ & $2,18 \mathrm{a}$ & & $2,24 \mathrm{a}$ & $2,29 \mathrm{a}$ & $2,17 \mathrm{a}$ & \\
\hline $\mathrm{CV}(\%)$ & 13 & & & & & & & \\
\hline
\end{tabular}

Médias seguidas por letras distintas, minúscula na horizontal e maiúscula na vertical, dentro de cada variável, diferem entre si, pelo teste de Tukey, a $5 \%$ de probabilidade. 
confirmando os resultados obtidos no presente trabalho para o híbrido.

$\mathrm{A}$ adição de $\mathrm{BAP}$ ao meio de cultura para a propagação in vitro de Laelia crispata influenciou significativamente, porém com efeito negativo no aumento da produção de nós por explante. O ANA, por outro lado, foi benéfico, obtendo-se maior número de internós com o acréscimo de $2,0 \mathrm{mg} \mathrm{L}^{-1}$ e mantendose a incubação no escuro. Resultados semelhantes foram obtidos no presente estudo para o híbrido de orquídea, em que os melhores resultados também foram obtidos na ausência de luz, com igual concentração da auxina e ausência de citocinina no meio de cultivo, uma vez que não houve significância para as concentrações testadas desse fitorregulador (Tabela 1B).

Os resultados obtidos neste trabalho para ambas as espécies demonstram o efeito benéfico da adição de ANA ao meio de cultura para a variável número de internós com incubação no escuro. Tais observações se devem, muito provavelmente, à ação estimuladora de intensa divisão celular proporcionada pelas auxinas (SUZUKI et al., 2004), fazendo com que seja potencializada a condição de escuro em que muitas plantas apresentam estiolamento caulinar. Essa é uma vantagem no processo de micropropagação, uma vez que, em escala comercial, obtém-se maior número de plantas, pois cada nó apresenta uma gema lateral, que poderá dar origem a um novo broto ou explante (KERBAUY et al., 1995).

Segundo RAMOS \& CARNEIRO (2007), resultados semelhantes foram obtidos em estudos com Cattleya mesquitae, sendo utilizada a mesma concentração de ANA, mas com a obtenção de reduzido número de nós que foram atribuídos ao pequeno período de incubação no escuro, o que leva a concluir que, havendo continuidade do cultivo in vitro, as gemas axilares presentes nos nós poderiam originar novas brotações, ou seja, seriam fontes de novos explantes a cada nó formado. A adição de $2,0 \mathrm{mg} \mathrm{L}^{-1}$ de ANA ao meio de cultura para a propagação in vitro de gengibre (Zingiber officinalis) também influenciou significativamente o aumento da produção de nós por explante (ARIMURA et al., 1997). Em micropropagação de abacaxizeiro, BARBOZA (1999) obteve até 16 nós por broto caulinar estiolado, ao passo que MOREIRA et al. (2003) observaram brotos estiolados de aproximadamente $12 \mathrm{~cm}$, que apresentaram entre $10 \mathrm{e}$ 12 nós.

\section{CONCLUSÃO}

O número de brotos e de internós em plântulas da orquídea (nativa e híbrida) foi significativamente superior no ambiente em ausência de luz independente da concentração do fitorregulador utilizado, e a espécie nativa apresentou maior número de internós com a utilização de $2,0 \mathrm{mgL}^{-1}$ de ANA na ausência de BAP, já a orquídea híbrida apresentou maior número de internós com a utilização de $2,0 \mathrm{mgL}^{-1}$ de ANA.

\section{REFERÊNCIAS}

ARIMURA, C.T. et al. Propagação in vitro de gengibre (Zingiber officinale Roscoe) por meio de segmentos nodais estiolados. In: CONGRESSO BRASILEIRO DE FISIOLOGIA VEGETAL, 6., 1997, Belém, Pa. Anais... Belém, SBFV, 1997. p.559561.

BARBOZA, S.B.S. C.; CALDAS, L.S. Estiolamento e regeneração na multiplicação in vitro do abacaxizeiro híbrido PE x SC-52. Pesquisa Agropecuária Brasileira, Brasilia, v.36, n.1, p. 417-423, 2001. Disponível em: <http://www.scielo.br/scielo.php?pid=S0100$204 X 2001000300004 \&$ script $=$ sci_arttext $\&$ tlng=es $>$. Acesso em: 28 jul. 2008. doi: 10.1590/S0100204X2001000300004.

BARBOZA, S.B.S.C. Comparação de protocolos para micropropagação do abacaxizeiro, Ananas comosus (L.) Merril. 1999. 76f. Dissertação (Mestrado em Fitotecnia) Curso de Pós-graduação em Fitotecnia, Universidade de Brasília, DF.

DINIZ, J.D.N. et al. Ácido giberélico (GA3) e 6Benzilaminopurina (BAP) no crescimento in vitro de Macela [Egletes viscosa (L.) Less.]. Ciência e Agrotecnologia, Lavras, v.27, n.4, p.934-938, 2003.

FERREIRA, D.F. SISVAR: um programa para análises e ensino de estatística. Revista Symposium, Lavras, v.6, n.1, p.36$41,2008$.

GRATTAPAGLIA, D.; MACHADO, M.A. Micropropagação. In: TORRES, A.C. et al. Cultura de tecidos e transformação genética de plantas. Brasília: Embrapa-SPI-CNPH, 1998. V.I, p.183-260.

KERBAUY, G.B. et al. Manutenção da atividade meristemática apical em caules de Catasetum (Orchidaceae) pelo etileno: implicações com uma nova estratégia de micropropagação. In: CONGRESSO BRASILEIRO DE FISIOLOGIA VEGETAL, 5., 1995, Lavras, MG. Anais... Lavras: SBFV, 1995. 563p. p.3.

KNUDSON, L. A new nutrient solution for the germination of orchid seed. American Orchid Society Bulletin, West Palm Beach, v.14, p.214-217, 1946.

MOK, M. C. et al. Cytokinins: biosynthesis, metabolism and perception. In vitro Cellular \& Developmental Biology Plant, Columbia, v.36, p.102-107, 2000.

MOREIRA, M.A. et al. Estiolamento na micropropagação do abacaxizeiro cv. Pérola. Ciência Agrotécnica, v.27, p.10021006, 2003. Disponível em: <http://www.editora.ufla.br/revista/ 27_5/art05.pdf>. Acesso em: 28 jul. 2008.

MURASHIGE, T.; SKOOG, F. A revised medium for rapid growth and bioassays with tobacco tissue cultures. Physiologia 
Plantarum, n.15, p.473-97, 1962. Disponível em: < http:// www.garfield.library.upenn.edu/classics 1978 / A1978FR51700002.pdf>. Acesso em: 28 jul. 2008.

RAMOS, T.V.; CARNEIRO, I.F. Multiplicação "in vitro" de Cattleya x mesquitae pelo método de estiolamento de segmentos caulinares. Pesquisa Agropecuária Tropical. Goiás, v.37, p.10-15, 2007. Disponível em: <http://200.137.221.132/ index.php/pat/article/viewArticle/1840>. Acesso em: 28 jul. 2008 .

RAVEN, P.H. et al. Biologia vegetal. Rio de Janeiro: Freeman, 2001. 906p.
SOUZA, G.M.; GONÇALVES, A.N. Otimização de meio de cultura para a bananeira (Musa cavendishii L.). Scientia Agricola, Piracicaba, v.53, n.1, p.51-59, 1996. Disponível em: <http:// w w w. s c i e lo.b r / s c i e 1 o.p h p ? p i d = S 0103 $90161996000100007 \&$ script=sci_arttext\&tlng= en $>$. Acesso em: 28 jul. 2008. doi:10.1590/S0103-90161996000100007.

SUZUKI, R.M. et al. Endogenous hormonal levels and growth of dark-incubated shoots of Catasetum fimbriatum. Journal of Plant Physiology, Stuttgart, v.161, p.929-935, 2004.

TAIZ, L.; ZEIGER, E. Fisiologia vegetal. 3.ed. Porto Alegre: Artmed, 2004. 722p. 